\title{
Matthew Durington Introduction: The Stakes of Whiteness Studies
}

The papers collected in this issue of Transforming Anthropology emerged from a panel at the American Anthropological Association meetings in 2006. The panel was titled Racism and Interrogations of Whiteness. The essays collected and expanded in thisissue and the next one, part of an invited session sponsored by the Association of Black Anthropologists, were presented with the challenge of contributing to an antiracist politics and discourse within anthropology by critically examining the historical and contemporary meanings of "white privilege"' and the sociopolitical contexts of politicized cultural constructions as manifested from different racial, class, gender, and national positions. The panelists continue to ask, along with Ruth Frankenberg (1993), why talk about whiteness at all, especially when this seemingly overdetermined intellectual undertaking can be seen as contributing to so much more conceptual reification. This is particularly true as the field of "critical whiteness studies" has increased exponentially in the last 18 plus years, especially if we use David Roediger's publication of Wages of Whiteness (1991) as a starting point for the whiteness studies bandwagon. But as the following essays demonstrate, a failure to critically engage the socalled unmarked status of whiteness, accepting the ostensible transparency of a privileged "white" positionality, creates even greater problems in terms of the asymmetry of power relations within our discipline, even as it perpetuates methodological blindness in our fieldwork practice. Further, it is imperative that anthropology continue to lead the way to a more complex, nuanced, and culturally situated analysis of racism, in general, and of whiteness (and its slippage into and out of other identificatory trajectories), in particular, because of the relationship between assumptions about whiteness and defenses of racist discourse and practice.

As Roediger has asserted, to simply focus on whiteness to the detriment of white racism and other power structures elides the political intent of this type of analysis (1991). These papers move the discussion from definitions and labels to an accounting of how American culture utilizes and reconstitutes whiteness in subtle material, ideological, and spatial ways. By arguing for a cross-sectional, multiethnic, and cross-class theorizing of race relations and racist ideology which includes Latinos, new immigrants, and the multiplicity of social realities that exist in the United States, a challenge is presented to anthropologists to rethink their assumptions about color, class, and white privilege within our current discipline and its conventional modes of professional practice.

Treatments of whiteness have been the subject of anthropological speculation for a number of years. While the history of anthropology has implicitly critiqued race (and white identity, specifically) for over a century, anthropology has more recently focused on ethnographic treatments of white identity, white populations and the transmutation of whiteness. These ethnographies have attempted to simultaneously critique the power of whiteness and provide "thick descriptions" of how whiteness has been constructed, disseminated through media, and made to intersect with an array of other social identities. For those who have taken up studies of whiteness, there are multiple positions that reflexively frame a particular antiracist militancy, irreverence or critical background.

Anthropology's main contribution to critical whiteness studies in the last two decades is to demonstrate that the construction of white identity consistently intersects and compounds an assortment of other social identities concomitantly at play within local contexts and situations. The ability to bring a sharp lens to the actual local places where whiteness is constructed and contested (as witnessed through the ethnographic encounter) enables anthropologists to engage whiteness in a critical fashion that removes it from the often blunt analysis of larger social spaces/scales of whiteness in other academic disciplines. An argument could be made that these analyses of whiteness that focus on larger societal factors fail to deal with the complexities of how varied whitenesses are actually lived in everyday life. Additionally, anthropology is also able to engage the emotive and sensory aspects of this lived experience better than most disciplines, and it is often within these realms that social "situations," 
racial or otherwise, occurFrevealing the actual working assumptions behind an assertion/contestation of white identity. In many ways, an antiracist social engagement with (and critique of) whiteness is best served by anthropological speculation.

It is important to note that the theme of whiteness being interrogated in this collection of essays is not meant to create some kind of artificial polarity with blackness, a faux polarity that might mistakenly be assumed to instantiate the focus of a journal published by the Association of Black Anthropologists. Rather, the interrogation of whiteness here is meant to show how this identity complex has produced slippage (Frankenberg 1993) that shows the complexity by which whiteness in its various manifestations intersects with other identity formations. In addition, our desire is also to show the continued strength of anthropological sensibilities vis-a whe thoughtful interrogation of "interpretive repertoires" (Hartigan 1999) of social life and their entanglement with rhetorics/realities of race. As such, the authors engage whiteness in multiple sites, including historical (Slocum/Hill), political (Fine and Ruglis), and emotive (Hartigan) manifestations as it intersects (or is imbued) with power. These analyses focus on whiteness with an eye toward a larger critique of racism in the United States. As Hartigan notes in this collection, we are witnessing a simultaneous moment where more critical attention is being paid to racial inequality, while racial inequality increasingly becomes the basis for sharper divisions in housing, hiring and other social realms. Thus, it is particularly important that a continued interrogation of whiteness, and of race, remains a fundamental emphasis of ethnographic writing and anthropological theory.

\section{REFERENCES CITED}

\section{Frankenberg, Ruth}

1993 White Women, Race Matters: The Social Construction of Whiteness. Minneapolis: University of Minnesota Press.

Hartigan, John

1999 Racial Situations: Class Predicaments of Whiteness in Detroit. Princeton: Princeton University Press.

Roediger, David

1991 The Wages of Whiteness: Race and the Making of the American Working Class. London: Verso. 
